\title{
A Preliminary Study on Gross Motor Performance of Hong Kong Children Aged 6-8 Years 香港六至八歲兒童大肌肉運動能力表現初步研究
}

\author{
Kang-chum CHOI TSE \\ Department of Physical Education \& Sports Science, \\ Hong Kong Institute of Education, HONG KONG \\ 蔡謝鏡珍 \\ 香港敉育學院體育及運動科學系
}

\begin{abstract}
Gross motor development is a critical component of elementary school physical education programs. This is also the foundation for active participation in later childhood and adult physical activities. This study aims to: (1) collect preliminary data on Hong Kong children's gross motor performance; (2) analyze Hong Kong Children's gross motor proficiency; and (3) introduce a gross motor test instrument to Hong Kong PE teachers. The Test of Gross Motor Development (Second Edition) (TGMD-2) (Ulrich, 2000) was chosen as the test instrument in this project. There were 15 girls and 15 boys selected for each age interval: $6-6$ to $6-11,7-6$ to $7-11$ and $8-0$ to $8-11$. Only $27.6 \%$ of the participants achieved the average level. $27.6 \%$ and $40 \%$ of them were below average and poor, respectively. No significant sex differences in the level of fundamental gross motor skills development. However, age differences were found in stationary dribble and overhand throw, 8 years old children got higher successful rate in the mature form of the two skills.
\end{abstract}

\section{摘 要}

大肌肉運動能力發展是小學體育課程的主要元素, 這亦是青少年及成年時期積極參與體力活動的基石。本研究的目的是：(1)搜 集香港兒童大肌肉運動能力數據；（2）分析香港兒童大肌肉運動能力表現；（3）介紹一套測試大肌肉運動能力的工具給香港體育老 師。本研究選用了 '第二代大肌肉運動能力(TGMD-2)' 作測試工具。每一個年齡組別, 即 6-6 至 6-11， 7-6 至 7-11 及 8-6 至 811 均選取 15 男及 15 女作為研究樣本。總樣本為 90 人。研究發現, 樣本中祇有 $27.6 \%$ 在一般水平, 另外 $27.6 \%$ 及 $40 \%$ 分別在低 於及差的水平。在大肌肉運動能力的表現中, 性別差異方面並不明顯。原地運球及擲球動作, 年齡差異較明顯, 八歲兒童成功掌握這 兩個技能的百份比較年幼的兒童為高。

\section{Introduction}

The purposes of assessing children's gross motor performance could be categorized into the following aspects, to understand children's gross motor proficiency in various skills; to compare the difference between sexes and age; to establish norms and references for assessment; to evaluate a teaching programs and to monitor and identify children's needs. In late 90s, educators had identified that the significance of assessment was beyond measuring or grading, it was to improve children's learning (Spackman, 2002). According to Gallahue (1996), motor assessment takes two forms: 'Process Assessment and Product Assessment', (Gallahue, 1996, p.183). Process assessment focuses on the qualitative aspects of movement form, style, or mechanics used to perform the motor skills. Product assessment focuses on the quantitative aspects of movement in terms of time, distance, or accuracy (Gallahue, 1996). Both assessment forms provide important data regarding the development and acquisition of motor skills. At the beginning of new skill learning, teachers have to pay attention to individual children's movement forms and body mechanics, once the skill is mastered the product will then be stressed. In assessing the qualitative aspects, performance-criteria must be listed for analyzing children's 
motor skills. Teachers who are familiar with the performancecriteria will have a clear picture of children's current performance and the desired movement form. This would help teachers to adapt their teaching strategies, provide feedback, and ultimately improve children's performance. If assessment is to assure positive and effective learning, teachers' knowledge in assessing children's motor performance is crucial. The next concern is what assessment tools should be used so as to enhance learning.

Cooley, Oakman, McNaughton, and Ryska (1997), used the Test of Gross Motor Development (TGMD) (Ulrich, 1985) to investigate the gross motor development of 7 to -10 -years old Tasmanian school children. The same test instrument was used in Dunedin primary school, New Zealand, to test the level of fundamental gross motor skill development of 10 years to 10 years 11 months children (Sanders and Kidman). In USA and other countries, Motor Skill Inventory (MSI) (Werder \& Bruininks, 1988) was another test instrument commonly used by professionals, to measure children's performance (Derri, Zissi \& Pachta, 2001; Rutledge 1993; Smith, Carlisle \& Cole. 1991). Both TGMD and MSI are American Tests.

In Hong Kong the implementation phase of Education Reform commenced last September 2001. The PE curriculum for the junior primary levels had focused on the teaching and learning of fundamental movement skills. Attention was drawn to the planning of a systematic PE program so as to help children to develop fundamental movement skills in the age of 6-8. On the other hand, physical educators aware that the methods and instruments being used to evaluate or assess children's fundamental movement skills are another critical issue needing detailed discussion. To cope with the educational changes, PE teachers expressed their concerns about the lack of knowledge regarding teaching and assessing children's fundamental movement skills.

Unlike western countries, study on children's fundamental movement skills or gross motor skills proficiency was limited in Hong Kong. Lam (1993) used the Cashin Test of Motor Development (Cashin 1975) to evaluate the effect of the PE program on Hong Kong Preschool children's gross motor performance. The Hong Kong Childhealth Foundation, a voluntary organization to promote children's health in Hong Kong, has introduced a physical fitness award scheme to the primary and secondary school students in 1990 so as to promote children's fitness. In 1993, the organization had explored the possibility of introducing the fitness award scheme to the preschool children aged 3-6 years old. To suit the developmental appropriateness of the preschool children a motor performance award scheme for Hong Kong kindergarten children was established (Lam, Ip \& Lui, 1997). The gross motor performance award scheme assessed preschool children's agility, dynamic balance, static balance and power. The award scheme was a widely accepted test instrument being used by the kindergarten teachers to test preschool children's gross motor performance in Hong Kong. The test measures children's gross motor ability, in terms of time, distance, or accuracy.

In attempting to review the literature of study on the gross motor performance of Hong Kong children, only one study was found in the preschool levels (Lam and Schiller 2001). For primary school children aged 6-12 years, no study was found. We have limited information in children's gross motor proficiency study, no test instrument for our culture, and no data for establishing local norms for teachers' reference. To take the first step several criteria on the selection of test instrument are being considered. For instance, (a) the reliability and validity of the test instrument; (b) ease of administration by PE teachers; (c) equipment and facilities are available in Hong Kong school settings, (d) the information and data for reference are beneficial to teaching; (e) knowledge to identify and monitor children's needs can be drawn from the test results. The TGMD (Ulrich, 1985) has received good comments and support from overseas researchers and physical educators. It was developed for the use of ioccupational therapists, physical therapists, diagnosticians, adapted and general physical education teachersî (Ulrich, 2000, p.3). After revision, the TGMD-2 (Ulrich, 2000) seems to be the most updated one in testing children's gross motor development. The test-retest reliability for the TGMD-2 is most desirable $(r=.86-.96)$ (Ulrich, 2000). The TGMD-2 provides both norm-referenced and criterion-referenced interpretations and emphasis is placed on the qualitative aspects of six locomotor skills (run, gallop, hop, leap, horizontal jump and slide) and six object control skills (underhand roll, twohand strike, bounce, catch, kick and overhand throw) acquisition.

The purpose of this study is to: (1) collect preliminary data on Hong Kong children's gross motor performance; (2) analyse Hong Kong Children's gross motor proficiency; and (3) introduce a gross motor test instrument for Hong Kong PE teachers. 


\section{Method}

\section{Participants}

Three schools sited in three different areas of Hong Kong, namely Hong Kong Island, Kowloon and New Territory were invited. There were 15 girls and 15 boys selected from each school for each age interval: 6-6 to 6-11, 7-6 to 7-11 and 8-0 to 8-11. Altogether there were ninety children involved in the study ( $\mathrm{n}=45$ girls, $\mathrm{n}=45$ boys). Permission was obtained from the School Principal to undertake the study in each school. An invitation letter was sent to each child and parent's consent was sought before the test was conducted.

\section{Procedures}

Guidelines based on the information provided in the test manual of the TGMD-2 (Ulrich, 2000) and the actual situation of Hong Kong schools environment were prepared by the research investigator. Two research assistants and ten student research assistants were trained to administer the test. The research assistants were responsible to explain and demonstrate the test items to the subjects by referring to the standard directions in the test manual. Student research assistants were responsible to video -tape all test items of each subject.

Each test lasts for approximately 90 minutes; same age group in the same school was tested at the same time. Participants of same sex were grouped together. One research assistant and one student research assistant were responsible to administer one subtest station. Participants were asked to perform the skill in turns. Due to the inexperienced background of the research investigator and the time constraint, assessment on spot was impossible and undesirable. Each of the tests was videotaped for further analysis. For the analysis of the performance criteria, one of the research assistants was trained. To refine the observation skills of researchers, the series of 'Assessment of fundamental motor skills' videos were used as the training tool (Ignico, 1994). After the training, the research assistants and the research investigator analysed the taped movement of each participants collected from this study, together. When an $80 \%$ agreement or above was obtained between the research investigator and the research assistant of each performance criteria, they started coding the videotapes, individually. After the coding, the degree of agreements of the two observers was tested by the Sign Test. 83\% agreements of the two observers were obtained based on the recorded judgments.

\section{Measures}

The Test of Gross Motor Development-2 (TGMD-2) (Ulrich, 2000) was used to assess children's gross motor performance. The TGMD-2 consists of two subtests; each subtest assesses six skills. One is the locomotor subtest (run, gallop, hop, leap, horizontal jump and slide) and the other is the object control subtest (underhand roll, two-hand strike, bounce, catch, kick and overhand throw). Each subject has to attempt two trails for each skill. Each gross motor skill includes 'several behavioural components that are presented as performance criteria' (Ulrich 2000, p.9). Each gross motor skill has three to five specific observable movement characteristics for that particular skill. For example, three performance criteria were listed out for assessing the 'Leap', whereas the 'Hop' skill had to master five performance criteria. If the child performs a behavioural component correctly, a mark ' 1 ' will be recorded in the record sheet, if the child does not perform correctly, mark ' 0 ' will be recorded. Each child has two trials to perform the skill. A raw skill score for each item is obtained by adding up all the ' 1 ' of the two trials (See Table 1). The overall raw scores were obtained by adding up all the '1's. The maximum score for locomotor skill subtest and object control skills subtest is 48 .

Table 1. Example of Skill Test Performance Record.

\begin{tabular}{|c|c|c|c|c|c|}
\hline Skill & & Performance Criteria & Trial 1 & Trial 2 & Score \\
\hline \multirow[t]{3}{*}{ Leap } & 1. & Take off on one foot and land on the opposite foot & 0 & 1 & 1 \\
\hline & 2. & A period where both feet are off the ground longer than running & 1 & 1 & 2 \\
\hline & 3. & Forward reach with the arm opposite the lead foot & 1 & 0 & 1 \\
\hline
\end{tabular}




\section{Results}

The raw score of the two subtests obtained from the TGMD-2 were converted into the Gross Motor Quotient (GMD) to determine the level of gross motor skill development among Hong Kong children. Seven levels of the gross motor skill development were categorised based on the GMD. Only one child has reached the 'Above Average Level'. $27.6 \%$ of the samples were at the 'Average Level' and 'Below Average Leve'. 40\% was at the 'Poor level' (see Figure 1). The results of an independent sample t-test equal variance indicated that there are no significant differences between boys and girls (see Figure 2). This is an interesting finding; in most studies differences between two sexes were significant. Boys performed better than girls (Cooley, 1997; Derri et al. 2001; Sanders, 1998; Walkley, 1993). Hong Kong boys outperformed girls in kicking, only.

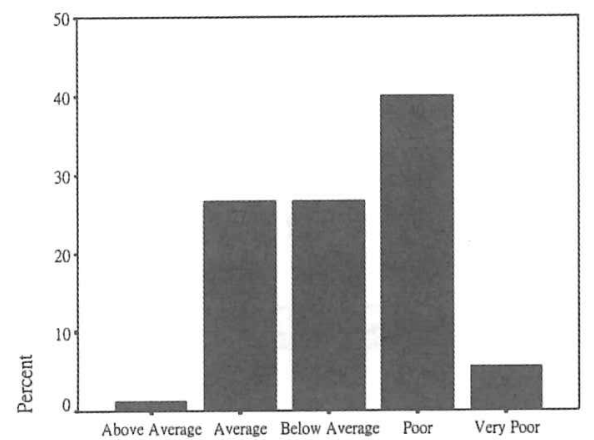

Figure 1.
Performance criteria of each gross motor skill represent a mature pattern of the skill. If a child got full marks in one of the tested skills, it meant that the child had acquired the mature form of that particular skill. Of the twelve skills tested, nearly $50 \%$ of the subjects had acquired the mature form of the skills in SLIDE $(n=59), \operatorname{RUN}(n=45)$ and STATIONERY DRIBBLE $(n=41)$. The under-developed skills were HOP $(n=2)$ only two children had obtained full marks in this skill, CATCH $(n=10)$ and UNDERHAND ROLL $(n=10)$. From the analysis and assessment of the children's performance, it was noticed that several movement components in the tested skills are difficult to master and some needed more attention when teaching the skill to children. Figure 3 had listed out those movement components that Hong Kong children had difficulty in mastering. More attention is needed for improving children's gross motor skills. With reference to the TGMD-2 Examiner's Manual, Hong Kong children had revealed the same problem as the USA children (Ulrich 2000, p.18-19).

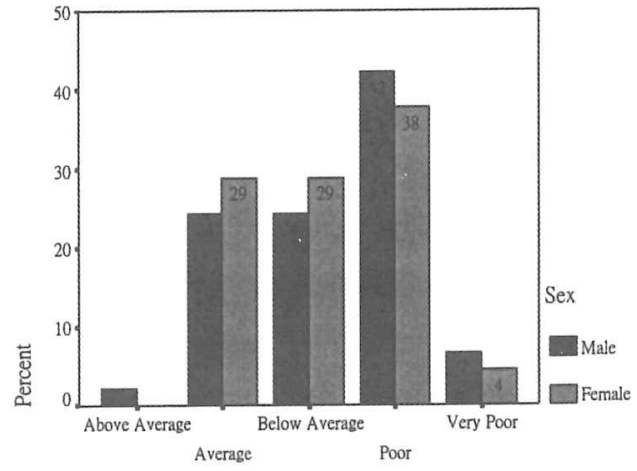

Figure 2.

Figure 3. Movement Components Need More Attention.

\begin{tabular}{|c|c|c|}
\hline Skills & Performance Criteria & $\begin{array}{l}\text { Percentage of mastery results } \\
\text { of the skills }(\%)(\mathrm{N}=90)\end{array}$ \\
\hline Gallop & Arms bent and lifted to waist level at take off & 15 \\
\hline \multirow[t]{2}{*}{ Hop } & $\begin{array}{l}\text { Non-support leg swings forward in pendular fashion } \\
\text { to produce force* }\end{array}$ & 17 \\
\hline & Arms flexed and swings forwards to produce force* & 12 \\
\hline Leap & Forward reach with the arm opposite the lead foot & 17 \\
\hline Horizontal Jump & $\begin{array}{l}\text { Preparatory movement includes flexion of both knee with } \\
\text { arms extended behind body }\end{array}$ & 36 \\
\hline " & $\begin{array}{l}\text { Arms extend forcefully forward and upward reaching } \\
\text { full extension above head }\end{array}$ & 30 \\
\hline \multirow[t]{2}{*}{ Catch } & $\begin{array}{l}\text { Preparation phase where hands are in front of the body } \\
\text { and elbows are flexed }\end{array}$ & 47 \\
\hline & Ball is caught by hands only & 40 \\
\hline Kick & An elongated stride or leap immediately prior to ball contact & 35 \\
\hline \multirow[t]{2}{*}{ Overhead } & Windup is initiated with downward movement of hand/arm & 14 \\
\hline & $\begin{array}{l}\text { Rotates hips and shoulders to a point where the non-throwing } \\
\text { side faces the wall }\end{array}$ & 37 \\
\hline
\end{tabular}

*Note: Very difficult to master. 


\section{Conclusion}

Helping children to develop fundamental gross motor skills has received a great deal of attention since the 80 's. Studies on the performance of children's gross motor performance have become a hot issue within these ten years. The studies in Australia and New Zealand both reported that children's motor proficiency were poor or incompetent (Cooley, 1997; Derri 2001; Sanders, 1998 \& Walkley, 1993). Consistent with previous studies conducted in other countries, performances of the children in Hong Kong (HK) were poor, too. We have limited records in studying HK children's gross motor performance; the present study did provide preliminary data on primary school children's gross motor performance. Apart from knowing the levels of performance of the HK children, the 'criteriareference' method being used in this study had drawn the research investigator's attention to the teaching of movement components of each skill. As shown in Figure 3, the percentage of mastery results of each skill has given the researcher information on which aspects of movement are efficient or deficient in the participants' motor skills, for instance, arms movements are not mastered in most locomotor skills. If we can identify the problem of children's motor behaviour, activities and tasks are designed to master the mature pattern; the quality of PE lessons will be enhanced. It has also alert the researcher to refocus the teaching strategies in the PE teacher education program on using the performance criteria as teaching guideline or teaching points in the fundamental movement skills learning and teaching activities.

It is highly recommended to introduce the TGMD-2 to PE teachers in HK for studying children's gross motor development. With a brief instruction and training, the TGMD-2 is easy to learn and easy to administer. Equipment and facilities are available in Hong Kong schools settings, except for the batting tee for testing 'Stationery striking'. Time spent in conducting the test is acceptable; it takes about 90minutes to complete the 12 items of 10 subjects. The teacher may choose to test only one item, which is related to the learning outcomes of the daily PE lesson, or a large scale study of individual schools.

\section{References}

Cashin, G. (1975). The Cashin test of motor development. Unpublished Master's Thesis, Bowling Green State University.

Cooley, D., Oakman, R., McNaughton, L. \& Rsyka, T. (1997). Fundamental movement pattern in Tasmania primary school children. Perceptual and Motor Skills, 84, 307-316.

Council, C. D. (2001). Learning to learn: Life-long learning and whole-person development. Hong Kong, Printing Department, Hong Kong Adminstrative Region of the People's Republic of China.

Derri, V., Zissi, V. \& Pachta, M. (2001). Development of manipulative skills by children in primary grades. Journal of Human Movement Studies 40, 377-390

Lam, H. M. Y. (1993). The effect of physical education on gross motor performance of Hong Kong preschool children. Education papers 16: Early childhood education in Hong Kong. S. Opper. Hong Kong, The Faculty of Education, University of Hong Kong: 53-66.

Lam, H. M. Y., Ip, H. M. H. \& Lui, P.K. (1997). A preliminary report on a modified set of motor performance tests for a motor performance award scheme for Hong Kong kindergarten children. Paper presented at the Australia Early Association National Triennial Conference, 20-23, September, 1997.

Lam, H. M. Y., \& Schiller, W. (2001). A pilot study on the gross motor proficiency of Hong Kong preschoolers aged 5 to 6 years. Early Child Development and Care, $171,11-20$.

Ignico, A. (1994). Assessment of Fundamental Motor Skills Videotape. Dubuque, IA: Brown \& Benchmark.

Rutledge, C. D. (1993). The level of motor skill development of preschool children provided a physical education program and preschool children provided with free play environments. School of Kinesiology and Physical education. Greeley, Colorado, University of Northern Colorado.

Sanders, L., \& Kidman, L. (1998). Can primary school children perform fundamental motor skills? Journal of Physical Education New Zealand, 31(4), 11-13. 
Smith, M., Carlisle, C., \& Cole, S. (1991). Teaching fundamental motor skills in the primary school: An examination of the effectiveness of a developmental physical education curriculum. Physical Education Review 14(2): 169-175.

Spackman, L. (2002). Assessment for learning: The lessons for physical education. British Association of Advisers and Lecturers in Physical Education, 38 (3), 179-183.

Ulrich, D. A. (1985). Test of gross motor development. Texas, Pro.ed.

Ulrich, D. A. (2000). Test of gross motor development. Texas, Pro.ed.

Walkley J., H. B., \& Probyn-Smith H. (1993). Fundamental motor skill proficiency of children. The ACHPER National Journal, Spring, 11-14.

Werder, J. K., \& Bruininks, R. H. (1988). Motor Skill Inventory. Circle Pine, Minnesota, America Guidance Service.

\section{Correspondence:}

Kang-chun CHOI TSE

Department of Physical Education \& Sports Science, Hong Kong Institute of Education, Tai Po, HONG KONG

Email: kcchoi@ied.edu.hk 